\title{
Biokinetic models for rats exposed to repeated inhalation of uranium: implications for the monitoring of nuclear workers
}

\author{
M. MONLEAU ${ }^{1}$, E. BLANCHARDON ${ }^{2}$, M. CLARAZ $^{1}$, F. PAQUET $^{1}$, V. CHAZEL $^{1}$
}

(Manuscript received 28 June 2005, accepted 11 November 2005)

\begin{abstract}
For dose assessment following chronic or accidental inhalation of radioactive aerosols, the dosimetric models of the International Commission on Radiological Protection (ICRP) provide dose coefficients, retention and excretion functions. Unknown date or dates of intake is the major source of uncertainty in dose assessment during routine monitoring of nuclear workers. The two assumptions commonly made in dose assessment from an unknown time pattern of intake have been tested experimentally with a model of repeated inhalation by rats. The hypothetical intake derived from lung measurement was relatively reliable under the two hypotheses. The hypothetical intake derived from excreta measurement depended on the choice of hypothesis and on the real time pattern of intake.
\end{abstract}

Key words: uranium / biokinetics / chronic exposure / inhalation / model

RÉSUMÉ Modèles biocinétiques chez le rat exposé à une inhalation répétée d'uranium : application à la surveillance des travailleurs du nucléaire.

Les modèles dosimétriques de la Commission internationale de protection radiologique (CIPR) permettent de calculer les coefficients de dose et les fonctions de rétention et d'excrétion utilisés pour l'estimation de la dose engagée suite à une inhalation chronique ou accidentelle d'aérosols radioactifs. La première source d'erreur dans l'estimation dosimétrique pour la surveillance de routine des travailleurs du nucléaire est l'inconnu sur la ou les dates d'incorporations. Aussi, les deux hypothèses le plus couramment utilisées pour estimer une dose résultant d'une incorporation à une date inconnue sont testées expérimentalement à partir d'un modèle d'inhalation répétée chez le rat. L'incorporation théorique calculée à partir des mesures de rétention pulmonaire est relativement fiable quelle que soit l'hypothèse choisie. L'incorporation théorique calculée à partir des mesures des excréta dépend du choix de l'hypothèse et du profil de contamination.

\section{Introduction}

Inhalation of airborne uranium compounds such as $\mathrm{UO}_{2}, \mathrm{UO}_{3}$ and $\mathrm{U}_{3} \mathrm{O}_{8}$ is one of the major considerations for the health protection of nuclear workers involved in

IRSN/DRPH/SRBE, Laboratoire de radiotoxicologie expérimentale, BP 166, 26702 Pierrelatte, France.

2 IRSN/DRPH/SDI, Laboratoire d'évaluation de la dose interne, BP 17, 92262 Fontenay-aux-Roses, France. 
uranium concentration, purification, enrichment and in fuel fabrication (Boffetta et al., 1991; Fulco et al., 2000; Chazel et al., 2001). After contamination, the systemic distribution of uranium cannot be directly measured in humans and must be inferred from the urinary or faecal uranium excretion rate using a biokinetic model (McDiarmid et al., 2002; Bailey et al., 2003; Stradling et al., 2003; McDiarmid et al., 2004). For contamination through inhalation, the human respiratory tract model described in ICRP publication 66 (ICRP, 1994) and the uranium systemic model of ICRP publication 69 (ICRP, 1995) are used to design monitoring programmes and interpret activity measurements (Bailey et al., 2003). These models are implemented to produce dose coefficients, retention and excretion functions.

Nuclear workers potentially exposed to radionuclides are monitored routinely at pre-determined time intervals. To interpret the monitoring data when no established incident took place, it is usually assumed that the possible intake happened at the middle of the monitoring interval (T/2 hypothesis). If chronic exposure is suspected, it is assumed that the intake occurred continuously (chronic hypothesis) during the entire monitoring interval (ICRP, 1997). Using the biokinetic model of uranium under either of these two hypotheses, can lead to under- or overestimation of the real intake and, consequently, of the assessed dose and risk.

This study uses experimental data to compare the known experimental intake with the estimations obtained under the two hypotheses about the plausible time pattern of exposure used for nuclear workers (chronic or T/2 hypothesis).

\section{Material and methods}

\subsection{Animals}

Sixteen-week old, pathogen-free adult male OFA Sprague Dawley rats weighing $562 \pm 26 \mathrm{~g}$ were obtained from Charles River Laboratories, France. General health parameters of the rats (animal weight, food and water consumption) were monitored weekly throughout the experiments. The study was conducted in accordance with French legislation on the protection of animals used for experimental purposes.

\subsection{Aerosol generation}

The industrial $\mathrm{UO}_{2}$ powder found at workplaces in uranium fuel cycle facilities was supplied by COGEMA (Pierrelatte, France). The $\mathrm{UO}_{2}$ characteristics were depleted insoluble (absorption Type $S$ ) uranium, specific alpha activity $=13 \times$ $10^{3} \mathrm{~Bq} \mathrm{~g}^{-1}$; density $=11.44 \mathrm{~g} \mathrm{~cm}^{-3}$; isotopic composition by mass: ${ }^{238} \mathrm{U}=$ $99.755 \%,{ }^{235} \mathrm{U}=0.244 \%,{ }^{234} \mathrm{U}=0.001 \%,{ }^{236} \mathrm{U}<0.0003 \%,{ }^{232} \mathrm{U}<0.00001 \%$. 
The instrument used for the $\mathrm{UO}_{2}$ aerosol generation was a Small-Scale Powder Disperser (SSPD, model 3433, TSI, St. Paul, MN 55164, USA). The concentration of particles in the inhalation chamber was calibrated by sampling onto membrane filters (pore size $0.8 \mu \mathrm{m}, 25 \mathrm{~mm}$ diameter, in cellulose acetate, Millipore). The particle size distribution of the aerosols administered to the rats was determined using an Andersen cascade impactor and an Aerodynamic Particle Sizer (APS, model 3310A, combined with a diluter, model 3302, TSI, USA). Sixty eight percent of the particles mass had an aerodynamic diameter from 0.4 to $9 \mu \mathrm{m}$. With the impactor, the aerodynamic median activity diameter (AMAD) was $2.53 \mu \mathrm{m}$ (geometric standard deviation, gsd $=1.93$ ). With the APS, the mass median aerodynamic diameter of the $\mathrm{UO}_{2}$ particles was $1.8 \mu \mathrm{m}(\mathrm{gsd}=1.66)$ and the number median aerodynamic diameter $=0.91 \mu \mathrm{m}(\mathrm{gsd}=1.48)$.

\subsection{Aerosol administration}

The aerosol administration was achieved using a nose-only inhalation system (Phalen et al., 1984; André et al., 1989; Monleau et al., in press). The rats were acclimatised to the housing facilities, metabolism cages and restraining tubes for at least two weeks. Following acclimatisation, repeated exposure started at twenty weeks of age. Animals were divided into two groups and exposed to repeated inhalations of $\mathrm{UO}_{2}$ (group $\mathrm{U}=15$ rats) or clean air (group $\mathrm{C}=12$ rats) respectively. Group $\mathrm{U}$ was repeatedly exposed by inhalation for one hour to $\mathrm{UO}_{2}$ with an aerosol concentration of $190 \mathrm{mg} \mathrm{m}^{-3}$ (lung intake around $200 \mu \mathrm{g}$ ), twice a week for three weeks ( 7 inhalations).

\subsection{Uranium measurement}

Rats were housed in metabolism cages for ten days post-exposure and then twice a week. Urine and faeces were collected every day. Three rats from group $\mathrm{U}$ were sacrificed 1, 3, 6, 15 and 30 days after the end of the repeated exposure and three rats from the control group $C$ were sacrificed at days 1, 3, 15 and 30. Rats were anaesthetised with isoflurane and exsanguinated via the abdominal artery. They were autopsied immediately to collect the lungs (with trachea). The collected samples were placed in separate bottles, weighed, frozen and maintained at $-20{ }^{\circ} \mathrm{C}$ until analysed for uranium concentration.

To analyse the uranium content, the samples were asked based on a previouslypublished method (Ejnik et al., 2000) and the uranium mass content was determined by Kinetic Phosphorescence Analysis (KPA), Chemcheck, Richland, VA, USA (Hedaya et al., 1997). 


\subsection{Rat inhalation model}

The Cyclomod software (Malarbet, 1998) was used to design and implement the biokinetic model of uranium in rats (Monleau et al., in press). Cyclomod predicts human urinary and faecal excretion of uranium and its retention in the ICRP biokinetic model compartments after a given intake. It is based on the models of ICRP publications 30, 66 and 69 (ICRP, 1979, 1994, 1995) and the algorithm described by Birchall and James (Birchall and James, 1987).

The transfer rates were adjusted to data from studies of acute intake of uranium by rats already published in the literature and reviewed by Leggett and Pellman (2003) and from an inhalation study of the acute intake of uranium by rats carried out in our laboratory (Monleau et al., in press). For the acute inhalation study, sixteen rats were exposed by inhalation for two hours to $\mathrm{UO}_{2}$ with an aerosol concentration of $375 \mathrm{mg} \mathrm{m}^{-3}$; the uranium biokinetics in organs and excreta were monitored at 1, 3, 6, 15 and 30 days post-exposure. The biokinetic parameter values of the Cyclomod software, which initially refers to the ICRP human reference values, were changed so that the predicted retention and excretion functions matched the experimental data from rat organ and excreta measurements after the acute inhalation (Monleau et al., in press). This rat inhalation model is used in this study to obtain the reference curves necessary to estimate the hypothetical intakes.

\subsection{Test of the two hypotheses used for monitoring programme}

During routine monitoring, when a positive measurement value is obtained and the time of intake within the monitoring period is unknown, it is usually assumed it took place at the middle of the monitoring interval ( $\mathrm{T} / 2$ hypothesis). For a monitoring interval $T$, the hypothetical intake is $M / m(T / 2)$, where $M$ is the measured quantity in lungs or excreta at the end of the monitoring interval and $\mathrm{m}(\mathrm{T} / 2)$ is the predicted value for an intake of $1 \mathrm{~Bq}$ that occurred at the mid-point of the monitoring interval T (ICRP, 1997). If chronic exposure is suspected, it can be assumed that the intake occurred continuously (chronic hypothesis) during the entire monitoring interval. In this case, the hypothetical intake is $\mathrm{M} / \mathrm{p}(\mathrm{T})$, where $\mathrm{M}$ is the measured quantity in lungs or excreta at the end of the monitoring interval and $\mathrm{p}(\mathrm{T})$ is the predicted value for a daily intake of $1 \mathrm{~Bq}$ that occurred throughout monitoring interval $\mathrm{T}$. The hypothetical intakes based on the biokinetic model were compared with the experimental intake.

Different contamination time patterns and monitoring intervals were considered. The monitoring interval was either smaller or larger than the experimental exposure time. In these different cases, the estimated experimental 

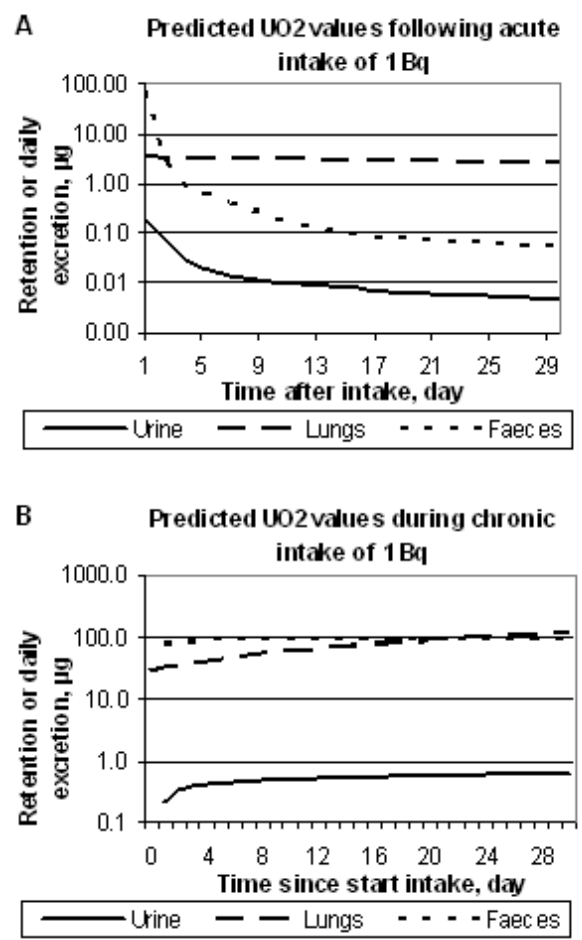

Figure 1 - Biokinetics of uranium dioxide in lungs ( $\mu \mathrm{g} / \mathrm{g}$ lungs), urine and faeces ( $\mu \mathrm{g})$ as predicted by the rat inhalation model as a function of days. Part A presents the reference biokinetics for the T/2 hypothesis: predicted retention and excretion values of $\mathrm{UO}_{2}$ following acute inhalation of $1 \mathrm{~Bq}$. $P$ art $B$ presents the reference biokinetics for the chronic hypothesis: predicted retention and excretion values of $\mathrm{UO}_{2}$ during continuous chronic inhalation of $1 \mathrm{~Bq} /$ day.

Biocinétique du dioxyde d'uranium dans les poumons, l'urine et les fèces prévu par le modèle d'inhalation chez le rat en fonction du temps.

intake was compared with the hypothetical intakes obtained under both hypotheses from lung or urine measurements.

\section{Results and discussion}

For routine monitoring of workers, only intake by inhalation is considered (ICRP, 1997). The reference uranium biokinetics for rats obtained from the rat inhalation model under the two hypotheses, mid-interval and chronic exposure, are illustrated in Figure 1 (respectively $\mathrm{A}$ and $\mathrm{B}$ ). These functions were used to calculate the hypothetical intakes. 
TABLE I

Test of two hypotheses for interpretation of routine monitoring of uranium in lungs and excreta. We postulate here that the monitoring interval is equal to the exposure period of 20 days. IA $\mathrm{T} / 2$ hypothesis, the hypothetical intake took place at day 10 , the middle of the monitoring interval. IB - Chronic intake hypothesis.

Essai de deux hypothèses pour l'interprétation de la surveillance de l'uranium dans les poumons et les excrétions.

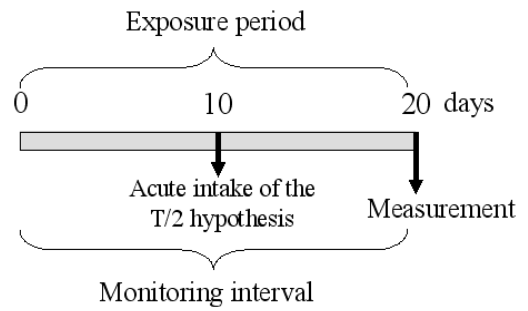

\begin{tabular}{|c|c|c|c|}
\hline & Lungs & Urine & Faeces \\
\hline \multicolumn{4}{|l|}{$\begin{array}{l}\text { IA }-\mathbf{T} / \mathbf{2} \text { Hypothesis } \\
T / 2=10 \text { days }\end{array}$} \\
\hline $\begin{array}{l}\text { Experimental retention ( } \mu \mathrm{g} / \mathrm{g} \text { lung) or daily excretion }(\mu \mathrm{g}) 1 \text { day } \\
\text { post-exposure }\end{array}$ & 600 & 15 & 3866 \\
\hline Predicted value 10 days after acute intake of $1 \mathrm{~Bq}(\mu \mathrm{g} / \mathrm{g}$ or $\mu \mathrm{g})$ & 2.99 & 0.01 & 0.22 \\
\hline Cumulated intake (Bq) & & 400 & \\
\hline Hypothetical intake (Bq) & 200 & 1500 & 17573 \\
\hline Hypothetical versus experimental intake & 0.5 & 3.8 & 44 \\
\hline \multicolumn{4}{|l|}{ IB - Chronic hypothesis } \\
\hline $\begin{array}{l}\text { Experimental retention ( } \mu \mathrm{g} / \mathrm{g} \text { lung) or daily excretion }(\mu \mathrm{g}) 1 \text { day } \\
\text { post-exposure }\end{array}$ & 600 & 15 & 3866 \\
\hline Predicted value ( $\mu \mathrm{g} / \mathrm{g}$ or $\mu \mathrm{g}$ ) for a daily intake of $1 \mathrm{~Bq}$ for 20 days & 91 & 0.56 & 90 \\
\hline Daily intake (Bq/day) & & 19 & \\
\hline Hypothetical intake (Bq/day) & 6.6 & 26.6 & 43 \\
\hline Hypothetical versus experimental intake & 0.35 & 1.4 & 2.3 \\
\hline
\end{tabular}

We first considered a monitoring interval equal to the experimental exposure time. Table I compares the experimental intake with the hypothetical intakes estimated from measurements in the lungs and excreta under both hypotheses.

Under the T/2 hypothesis, the hypothetical intake derived from the lung measurement supplied the most realistic estimation, although the intake was slightly underestimated by a factor of two. The hypothetical intakes derived from 
excreta measurements were overestimated from the urine measurement (by about a factor of 4) to highly overestimated from the faecal measurement (by a factor of 44). This significant overestimation of intake derived from faecal measurement can probably be explained by the high faecal excretion by rats in the first day (data no shown). This very rapid faecal excretion kinetics observed in rats makes it difficult to extrapolate this result to humans. Under the chronic hypothesis, the hypothetical intake derived from the lung measurement showed little variation and the estimations from excreta measurements were more realistic.

As a conclusion, whatever the hypothesis, the theoretical intake derived from the lung measurement is reasonable but slightly underestimated. But lung measurements are not often used in practice, because only very large intakes can be detected by direct in vivo measurement. Although uranium dioxide is relatively insoluble, the estimation of the intake from urine measurement is correct, with an overestimation by a factor lower than 4 . The estimation of uranium intakes and doses from urine samples are very sensitive to the dissolution rate in the lungs. On the other hand, the estimation from faecal measurement is reasonable only under the chronic hypothesis.

In the second case-study, the intake from lung and urine measurements was estimated for a monitoring interval being ten days longer than the exposure period. The contamination period may take place at the beginning or at the end of the monitoring interval. Experimental and theoretical intakes were compared under both hypotheses from lung (Tab. II) and urine (Tab. III) measurements.

From the lung measurement, the hypothetical intakes were underestimated (by a factor of 2 to 4 ) regardless of the hypothesis and the position of the exposure period in the monitoring interval. The T/2 hypothesis may seem a little better (underestimation only by a factor of 2 ) but with no significant advantage on the chronic hypothesis. From the urine measurement, the hypothetical intakes were underestimated when the exposure period was at the beginning of the monitoring interval, all the more if the chronic hypothesis was applied (by a factor of 15). However, when the exposure period was at the end of the monitoring interval, the hypothetical intakes were overestimated and the $T / 2$ hypothesis overestimated the intake more (by a factor around 5) than the chronic hypothesis (by a factor of 1.3).

In conclusion, the hypothetical intakes derived from lung measurement were fairly insensitive to a possible error in estimating the exposure period, unlike the hypothetical intakes derived from urine measurement.

In the third case-study, the intakes from lung and urine measurements were estimated for a monitoring interval being ten days shorter than the exposure period. 
TABLE II

Test of two hypotheses for interpretation of routine monitoring of uranium in lungs. We postulate here that the monitoring interval is 10 days longer than the exposure period. Exposure period $=$ 20 days; monitoring interval $=30$ days. IIA $-\mathrm{T} / 2$ hypothesis, the hypothetical intake took place at day 15, the middle of the monitoring interval. IIB - Chronic intake hypothesis.

Essai de deux hypothèses pour l'interprétation de la surveillance de l'uranium dans les poumons.

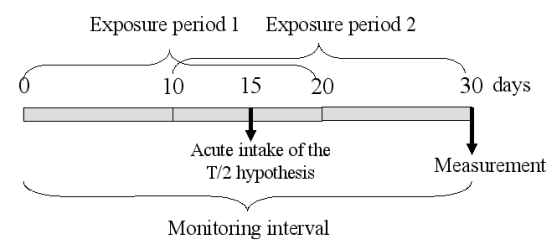

\begin{tabular}{|c|c|c|}
\hline & $\begin{array}{c}\text { Exposure (1) at } \\
\text { beginning of interval }\end{array}$ & $\begin{array}{c}\text { Exposure (2) at end } \\
\text { of interval }\end{array}$ \\
\hline \multicolumn{3}{|l|}{$\begin{array}{l}\text { IIA - T/2 Hypothesis } \\
T / 2=15 \text { days }\end{array}$} \\
\hline Experimental retention in lungs $(\mu \mathrm{g} / \mathrm{g})$ & $\begin{array}{l}10 \text { days post-exposure } \\
550\end{array}$ & $\begin{array}{c}1 \text { day post-exposure } \\
600\end{array}$ \\
\hline Predicted value 15 days after acute intake of $1 \mathrm{~Bq}(\mu \mathrm{g} / \mathrm{g})$ & 2.85 & 2.85 \\
\hline Cumulated intake (Bq) & \multicolumn{2}{|c|}{400} \\
\hline Hypothetical intake $(\mathrm{Bq})$ & 193 & 210 \\
\hline Hypothetical versus experimental intake & 0.48 & 0.53 \\
\hline \multicolumn{3}{|l|}{ IIB - Chronic hypothesis } \\
\hline Experimental retention in lungs $(\mu \mathrm{g} / \mathrm{g})$ & $\begin{array}{l}10 \text { days post-exposure } \\
550\end{array}$ & $\begin{array}{c}1 \text { day post-exposure } \\
600\end{array}$ \\
\hline Predicted value $(\mu \mathrm{g} / \mathrm{g})$ for a daily intake of $1 \mathrm{~Bq}$ for 30 days & 114 & 114 \\
\hline Daily intake (Bq/day) & \multicolumn{2}{|c|}{19} \\
\hline Hypothetical intake (Bq/day) & 4.8 & 5.3 \\
\hline Hypothetical versus experimental intake & 0.25 & 0.28 \\
\hline
\end{tabular}

The monitoring interval may take place at the beginning or at the end of the exposure period. When the monitoring interval is at the beginning of the exposure period, the situation is comparable to the scenario described in Table I with a shorter exposure period corresponding to the monitoring interval. The case where the monitoring interval is at the end of the exposure period could correspond to the situation of a past contamination not detected during the previous monitoring or to the first monitoring of a worker contaminated elsewhere. Experimental and theoretical intakes from lung and urine measurements were compared under both 


\section{TABLE III}

Test of two hypotheses for interpretation of routine monitoring of uranium in urine. We postulate here that the monitoring interval is $\mathbf{1 0}$ days longer than the exposure period. Exposure period = 20 days; monitoring interval $=30$ days. IIIA - T/2 hypothesis, the hypothetical intake took place at 15 days, the middle of the monitoring interval. IIIB - Chronic intake hypothesis.

Essai de deux hypothèses pour l'interprétation de la surveillance de l'uranium dans les urines.

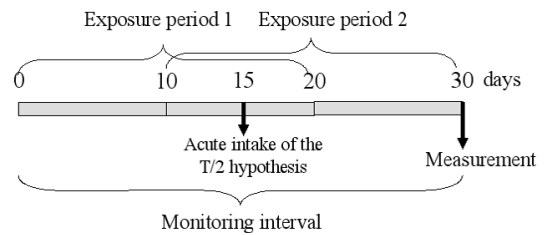

\begin{tabular}{|c|c|c|c|}
\hline & \multicolumn{2}{|c|}{ Exposure (1) at beginning of interval } & Exposure (2) at end of interval \\
\hline \multicolumn{4}{|l|}{$\begin{array}{l}\text { IIIA - T/2 Hypothesis } \\
T / 2=15 \text { days }\end{array}$} \\
\hline Experimental daily excretion in urine $(\mu \mathrm{g})$ & $\begin{array}{l}10 \text { days post-exposure } \\
0.75\end{array}$ & & $\begin{array}{l}1 \text { day post-exposure } \\
15\end{array}$ \\
\hline $\begin{array}{l}\text { Predicted value } 15 \text { days after } \\
\text { acute intake of } 1 \mathrm{~Bq}(\mu \mathrm{g})\end{array}$ & 0.0078 & & 0.0078 \\
\hline Cumulated intake $(\mathrm{Bq})$ & & 400 & \\
\hline Hypothetical intake (Bq) & 96 & & 1923 \\
\hline Hypothetical versus experimental intake & 0.24 & & 4.8 \\
\hline \multicolumn{4}{|l|}{ IIIB - Chronic hypothesis } \\
\hline Experimental daily excretion in urine $(\mu \mathrm{g})$ & $\begin{array}{l}10 \text { days post-exposure } \\
0.75\end{array}$ & & $\begin{array}{l}1 \text { day post-exposure } \\
15\end{array}$ \\
\hline $\begin{array}{l}\text { Predicted value }(\mu \mathrm{g}) \text { for a daily intake of } \\
1 \mathrm{~Bq} \text { for } 30 \text { days }\end{array}$ & 0.612 & & 0.612 \\
\hline Daily intake (Bq/day) & & 19 & \\
\hline Hypothetical intake (Bq/day) & 1.23 & & 24.5 \\
\hline Hypothetical versus experimental intake & 0.065 & & 1.3 \\
\hline
\end{tabular}

hypotheses when the monitoring interval is at the end of the exposure period (Tab. IV).

Regardless of the hypothesis, the hypothetical intakes were underestimated (by a factor around 2) when estimated from lung measurement and were overestimated (by a factor around 2) when estimated from urine measurement. 


\section{TABLE IV}

Test of two hypotheses for interpretation of routine monitoring of uranium in lungs and urine. We postulate here that the monitoring interval is $\mathbf{1 0}$ days shorter than the exposure period of 20 days. IVA - T/2 hypothesis, the hypothetical intake took place at the middle of the monitoring interval (day 5) which corresponds to 15 days of exposure. IVB - Chronic intake hypothesis.

Essai de deux hypothèses pour l'interprétation de la surveillance de l'uranium dans les poumons et les urines.

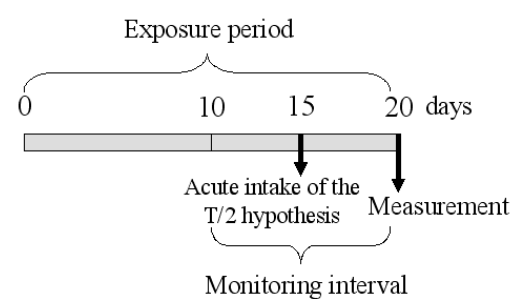

\begin{tabular}{|c|c|c|}
\hline & Lungs & Urine \\
\hline \multicolumn{3}{|l|}{$\begin{array}{l}\text { IVA }-\mathbf{T} / 2 \text { Hypothesis } \\
T / 2=5 \text { days }\end{array}$} \\
\hline $\begin{array}{l}\text { Experimental retention }(\mu \mathrm{g} / \mathrm{g} \text { lung) or daily excretion }(\mu \mathrm{g}) 1 \text { day } \\
\text { post-exposure }\end{array}$ & 600 & 15 \\
\hline Predicted value 5 days after acute intake of $1 \mathrm{~Bq}(\mu \mathrm{g} / \mathrm{g}$ or $\mu \mathrm{g})$ & 3.15 & 0.02 \\
\hline Cumulated intake $(\mathrm{Bq})$ & \multicolumn{2}{|c|}{400} \\
\hline Hypothetical intake $(\mathrm{Bq})$ & 190 & 750 \\
\hline Hypothetical versus experimental intake & 0.47 & 1.9 \\
\hline \multicolumn{3}{|l|}{ IVB - Chronic hypothesis } \\
\hline $\begin{array}{l}\text { Experimental retention }(\mu \mathrm{g} / \mathrm{g} \text { lung) or daily excretion }(\mu \mathrm{g}) 1 \text { day } \\
\text { post-exposure }\end{array}$ & 600 & 15 \\
\hline Predicted value ( $\mu \mathrm{g} / \mathrm{g}$ or $\mu \mathrm{g}$ ) for a daily intake of $1 \mathrm{~Bq}$ for 10 days & 60 & 0.48 \\
\hline Daily intake (Bq/day) & \multicolumn{2}{|c|}{19} \\
\hline Hypothetical intake (Bq/day) & 10 & 31 \\
\hline Hypothetical versus experimental intake & 0.5 & 1.6 \\
\hline
\end{tabular}

\section{Conclusions}

In case of inhalation of an insoluble uranium compound, the hypothetical intake derived from the lung measurement is relatively reliable under both $\mathrm{T} / 2$ and chronic hypotheses used in monitoring programmes, as it is only lightly affected by the contamination time pattern. The main disadvantage is that the limit of detection of uranium by lung measurement is rather high (at least $20 \mathrm{~Bq}$ ). 
BIOKINETIC MODELS FOR RATS EXPOSED TO REPEATED INHALATION OF URANIUM

The hypothetical intake from excreta measurement depends much on the assumption on the time of intake. Assuming the most realistic contamination time pattern has a fundamental impact on the reliability of intake and dose assessments. The chronic hypothesis is more realistic if the monitoring interval is similar to the actual contamination period. Otherwise, the T/2 hypothesis is more conservative, as it tends to overestimate the intake in the majority of cases or to underestimate it only slightly.

The monitoring programmes must take into account the possible contamination type, the sensitivity of the measurement techniques and the biokinetics of the radionuclide to specify a monitoring interval that allows a reasonably accurate estimation of intakes when the time of exposure is unknown.

Acknowledgments. We wish to thank O. Delissen, B. Dhieux, C. Maubert, and A.M. Moreels for their assistance during exposure, euthanasia and dissection. This work was partially supported by COGEMA (DOSINTER programme).

\section{REFERENCES}

André S., Charuau J., Rateau G., Vavaseur C., Métivier H. (1989) Design of a new inhalation device for rodents and primates, J. Aeros. Sci. 20, 647-656.

Bailey M.R., Ansoborlo E., Guilmette R.A., Paquet F. (2003) Practical application of the ICRP Human Respiratory Tract Model, Radiat. Prot. Dosim. 105, 71-76.

Birchall A., James A.C. (1987) A general algorithm for solving compartmental models with constant coefficients and its implementation on a microcomputer, National Radiological Protection Board. NRPB-R216. Chilton.

Boffetta P., Cardis E., Vainio H., Coleman M.P., Kogevinas M., Nordberg G., Parkin D.M., Partensky C., Shuker D., Tomatis L. (1991) Cancer risks related to electricity production, Eur. J. Cancer 27, 1504-1519.

Chazel V., Houpert P., Paquet F., Ansoborlo E. (2001) Effect of absorption parameters on calculation of the dose coefficient: example of classification of industrial uranium compounds, Radiat. Prot. Dosim. 94, 261-268.

Ejnik J.W., Hamilton M.M., Adams P.R., Carmichael A.J. (2000) Optimal sample preparation conditions for the determination of uranium in biological samples by kinetic phosphorescence analysis (KPA), J. Pharm. Biomed. Anal. 24, 227-235.

Fulco C.E., Liverman C.T., Sox H.C. (2000) Depleted Uranium, Gulf War and Health.1. Depleted uranium, Pyridostigmine bromide, Sarin and Vaccines: 89-168. Fulco, Liverman and Sox. National Academies press, Washington.

Hedaya M.A., Birkenfeld H.P., Kathren R.L. (1997) A sensitive method for the determination of uranium in biological samples utilizing kinetic phosphorescence analysis (KPA), J. Pharm. Biomed. Anal. 15, 1157-1165.

ICRP publication 30 (1979) Limits for intakes of radionuclides by workers, part 1, Ann. ICRP 2, 3-4.

ICRP publication 66 (1994) Human respiratory tract model for radiological protection, Ann. ICRP 24, $1-3$.

ICRP publication 69 (1995) Age-dependent doses to members of the public from intake of radionucleides: Part 3 Ingestion dose coefficients, Ann. ICRP 25, 1. 
ICRP publication 78 (1997) Individual monitoring for internal exposure of workers, Ann. ICRP 27, 3-4. Leggett R.W., Pellmar T.C. (2003) The biokinetics of uranium migrating from embedded DU fragments, J. Environ. Radioact. 64, 205-225.

Malarbet J.L. (1998) Calculations of radionuclide organ retentions from ICRP biokinetic recycling models, Radiat. Prot. Dosim. 79, 379-381.

McDiarmid M.A., Hooper F.J., Squibb K., McPhaul K., Engelhardt S.M., Kane R., DiPino R., Kabat M. (2002) Health effects and biological monitoring results of Gulf War veterans exposed to depleted uranium, Mil. Med. 167 (Suppl. 2), 123-124.

McDiarmid M.A., Squibb K., Engelhardt S.M. (2004) Biologic monitoring for urinary uranium in gulf war I veterans, Health Phys. 87, 51-56.

Monleau M., Blanchardon E., Claraz M., Paquet F., Chazel V. (in press) The effect of repeated inhalation on the distribution of uranium in rats, J. Toxicol. Environ. Health.

Phalen R.F., Mannix R.C., Drew R.T. (1984) Inhalation exposure methodology, Environ. Health Perspect. 56, 23-34.

Stradling N., Hodgson A., Ansoborlo E., Berard P., Etherington G., Fell T., LeGuen B. (2003) Optimising monitoring regimens for inhaled uranium oxides, Radiat. Prot. Dosim. 105, 109114. 